\title{
Proposta de construção de espectroscópio como alternativa para o ensino de Astronomia ${ }^{+*}$
}

Lucas Guimarães Barros ${ }^{1}$

Mestrando em Ensino de Ciências

Universidade Estadual Paulista "Júlio de Mesquita Filho" - Campus de Bauru Alice Assis ${ }^{2}$

Faculdade de Engenharia

Universidade Estadual Paulista "Júlio de Mesquita Filho"

Guaratinguetá - SP

Rodolfo Langhi ${ }^{3}$

Faculdade de Ciências

Universidade Estadual Paulista "Júlio de Mesquita Filho" - Campus de Bauru Bauru - SP

\section{Resumo}

Este trabalho apresenta uma proposta para o ensino de Astronomia em sala de aula, por meio da construção de espectroscópio simples e de baixo custo, a ser construído e utilizado pelos estudantes para demonstração do espectro eletromagnético de diferentes fontes luminosas. Dentre as inúmeras possibilidades de uso do espectroscópio para o ensino de diversos temas pertinentes à Física, Astronomia e Química, destacase o ensino de conceitos relativos à espectroscopia. Apresenta-se fundamentação teórica sobre ensino de física e astronomia, bem como a inserção de atividades experimentais para o ensino dessas duas ciências, e o uso de materiais de baixo custo como alternativa para o ensino laboratorial. Em seguida, discute-se a técnica da espectroscopia, os fundamentos físicos que a constituem e as aplicações da mesma. Por fim, descre-

\footnotetext{
${ }^{+}$Building a spectroscope as way for teaching of Astronomy

* Recebido: março de 2016. Aceito: julho de 2016.

1 E-mail: lucas.gbarros100@gmail.com

2 E-mail: alice@feg.unesp.br

${ }^{3}$ E-mail: rlanghi@fc.unesp.br
} 
ve-se a montagem do instrumento, sua utilização em sala de aula e sugestões de uso e abordagem oferecidas ao professor.

Palavras-chave: Espectroscopia; Materiais de baixo custo; Ondas eletromagnéticas; Ensino de Astronomia; Ensino de Física.

\begin{abstract}
This work presents a proposal to teaching spectroscopy in the classroom, through the building of a simple and low coast spectroscope, to be used by students for demonstration of electromagnetic spectrum of different bright sources. Among the several potentials for the spectroscope use in the teaching of some relevant subjects related to Physics, Astronomy and Chemistry, we stand out the teaching concepts of Astronomy. We introduce the theoretical foundations about Physics and Astronomy teaching, as well as insertion of experimental activities to teaching these two sciences, and the use of low coast materials as a laboratory teaching alternative. Then, we discuss the spectroscopy's technique, the physical foundations that are composed, and its applications. Finally, we describe the instrument assembly, its use in the classroom, and suggestions and approaches uses offered to the teacher.
\end{abstract}

Keywords: Spectroscopy; Low coast materials; Electromagnetic Waves; Teaching Astronomy; Teaching Physics.

\title{
I. Introdução e fundamentação teórica
}

Embora se possa constatar crescimento expressivo das pesquisas em Ensino de Física nas últimas décadas, o ensino dessa disciplina no Ensino Médio ainda atravessa diversos problemas, dos quais destacamos dois que consideramos recorrentes: i) dificuldade dos professores em abordar, de maneira adequada, os conteúdos de Astronomia (LANGHI, 2009; LANGHI; NARDI, 2005) e; ii) utilização de atividades experimentais mediante abordagens metodológicas inadequadas (SILVA; ASSIS, 2012).

No que tange às atividades experimentais, ainda que se reconheça o potencial e as possibilidades de uso dessas em sala de aula, é comum deparar-se com diversas dificuldades no ambiente escolar a elas associadas. Partindo da análise de relatos de experiências pedagógicas entre os anos de 1971 a 2006, Pena e Ribeiro Filho (2009, p.7-8) mapearam algumas dificuldades relatadas por pesquisadores da área de ensino quanto ao uso de atividades experimentais. Dentre os diversos problemas relacionados, evidenciados pelos autores, encontramse: a) carência de pesquisas sobre $o$ que os alunos aprendem mediante a utilização de experi- 
mentos; b) falta de preparo do professor para trabalhar com atividades experimentais; c) condições precárias de trabalho; e d) falta de apoio material e pedagógico das escolas.

Em se tratando do ensino de conceitos de Astronomia, a literatura especializada tem evidenciado dificuldades diversas enfrentadas pelos professores em sala de aula, tanto no que diz respeito à abordagem de conteúdos de Astronomia, quanto à presença de lacunas na formação inicial de professores (LANGHI; NARDI, 2005). Na realidade escolar, o livro didático, enquanto uma das principais fontes utilizadas pelo professor para uso em sala de aula e planejamento das aulas, apresenta erros conceituais em relação a diversos conteúdos da Astronomia, como por exemplo, concepções equivocadas sobre movimentos da Terra, constelações, dimensões dos astros e representações do Sistema Solar (LANGHI; NARDI, 2007).

Diante desse contexto, propomos neste trabalho a utilização de um instrumento de fácil construção - o espectroscópio - como ferramenta para o ensino de Astronomia, cujos conceitos são abordados no tema estruturador "Universo, Terra e Vida", presente nas Orientações Educacionais Complementares aos Parâmetros Curriculares Nacionais (BRASIL, 2000). Esse tema estruturador é subdividido em três unidades, em que são sugeridos diversos subtemas da Astronomia, tais como, Terra e Sistema Solar, Universo e sua origem e compreensão humana do Universo. De maneira específica, respaldamos a proposta de construção do espectroscópio na unidade sobre o Universo e sua origem, a qual especifica a necessidade de o aluno "conhecer as teorias e modelos propostos para a origem, evolução e constituição do Universo, além das formas atuais para sua investigação e os limites de seus resultados, no sentido de ampliar sua visão de mundo" (BRASIL, 2000, p. 31, grifo nosso), uma vez que a espectroscopia é uma das principais e mais poderosas ferramentas utilizadas pelos astrônomos para a investigação dos astros. Não é por acaso que o desenvolvimento da espectroscopia se dá em um período interino ao nascimento da Física Moderna (MATHIEU, 1971).

Para além das orientações curriculares, salientamos ainda alguns aspectos que consideramos justificadores para o ensino de Astronomia, como aqueles apresentados por Caniato (1974), apud Langhi (2009): a) desenvolvimento de habilidades úteis aos ramos do saber e da ciência; b) oportunidade de uma visão geral do desenvolvimento do conhecimento humano a respeito do Universo, e; c) oportunidade de desenvolver atividades práticas que não exigem materiais ou laboratórios dispendiosos.

A Astronomia se ocupa tanto do entender como funciona nosso "berço", a Terra, quanto todo o ambiente que o cerca. Esse ambiente vai se tornando cada vez maior, com o crescimento de nosso entendimento. A história da vida sobre a terra é o capítulo mais recente da história muito anterior e que tem a ver as origens dos planetas, sua relação com o Sol e deste com o "resto", o Universo (CANIATO, 2013, p. 7-8).

Langhi e Nardi (2012) salientam, também, o papel motivador intrínseco que a Astronomia pode proporcionar ao suscitar do imaginário popular as mais diferentes concepções que 
propiciam apreço e curiosidade por essa ciência. Tais características podem ser motivadoras tanto para o professor, como também para os alunos.

\begin{abstract}
[...] Muitos dos fenômenos observados no universo nunca foram, e nem costumam ser, encontrados na Terra; os alunos não podem "tocar", na maioria dos materiais astronômicos para serem adequadamente analisados. Sendo uma ciência basicamente visual, o professor precisa fazer uso de figuras, fotos, vídeos, maquetes etc., como recursos didáticos apropriados ao seu ensino. [...] presta-se adequadamente de tema central e motivador para a elaboração de grupos de estudos (ou "clubes"), promovendo a cidadania e relações interpessoais e sociais, além de estabelecer relações com outras ciências; [...] o seu laboratório natural é o céu, o que favorece a prática das observações a olho nu e com instrumentos (telescópios, binóculos etc.). (LANGHI; NARDI, 2012, p. 161-162).
\end{abstract}

Destacamos, por fim, o potencial interdisciplinar agregado à Astronomia, como salientado por Langhi (2014, p. 62), ao possibilitar o desenvolvimento de "atividades que envolvam conteúdos de outras disciplinas normalmente fragmentadas pelo currículo, (...) apoiandose em problematizações locais e sociais".

\title{
I.1 Atividades experimentais no ensino de Física e Astronomia
}

$\mathrm{O}$ ensino experimental de Física guarda rica história. Longe de esgotar o assunto, tomamos como ponto de partida deste tema as ações do extinto projeto $\mathrm{PSSC}^{4}-$ Physical Science Study Committee - desenvolvido no final dos anos 1950, nos Estados Unidos, destinado a superar a defasagem educacional norte-americana em conteúdos de Ciências e formar novos cientistas. As atividades experimentais desenvolvidas pelo referido Projeto, permitiam ao aluno efetuar manipulações nos experimentos organizados em kits, contendo guias para explicação do funcionamento dos equipamentos e informações relacionadas à atividade experimental (FERREIRA et. al., 2011, p. 3). Todavia, o PSSC e outros projetos de mesma envergadura (e.g.: Projeto Nuffield) encontraram problemas, com destaque à visão empírico-indutivista do conhecimento científico presente em seus materiais, caracterizada pela crença no nascimento da teoria a partir do experimento (PACHECO, 1997, p. 10; HODSON, 1985).

Todavia, consideramos inegável o potencial e a importância das atividades experimentais no ensino de Física/Astronomia, ao favorecer a aquisição de conceitos, procedimentos e desenvolvimento de habilidades, além de estimular a formação de uma imagem não ingênua do conhecimento científico. Atividades experimentais podem proporcionar ao aluno a oportunidade de "expressar suas concepções dos fenômenos de forma direta, experimental, ou

\footnotetext{
${ }^{4}$ Os materiais do PSSC foram traduzidos para o português e utilizados em diversas escolas brasileiras em meados dos anos 1960. O I SNEF, realizado em 1970 na cidade de São Paulo, buscou discutir os problemas encontrados na utilização do referido projeto na realidade escolar brasileira. As atas do evento estão disponíveis em: <http://www.sbfisica.org.br/v1/arquivos_diversos/SNEF/I/I-SNEF-Boletim.pdf>.
} 
de forma indireta, através dos registros desses fenômenos" (PACHECO, 1997, p. 10), sendo o laboratório o ambiente comum de desenvolvimento dessas atividades.

Em levantamento de trabalhos relacionados a atividades experimentais, Araújo e Abib (2003) buscaram analisar as propostas de atividades experimentais no Ensino de Física, e como a literatura tem discutido a importância da atividade experimental nessa perspectiva. Os autores categorizaram os trabalhos analisados de acordo com a ênfase matemática empregada no experimento, o grau de direcionamento das atividades, o uso de novas tecnologias, a relação com o cotidiano, e a montagem de equipamentos. Nos resultados da análise, emergiram diversas categorias relativas às atividades experimentais quanto ao grau de direcionamento, sendo essas do tipo: a) demonstração - ilustração de aspectos físicos, de modo que sejam perceptíveis aos alunos; b) verificação - busca, por meio de um determinado experimento, da validade de uma lei física e das suas limitações; e c) investigação - apresentação de problemas abertos ao aluno, de modo que ele busque resolvê-los mediante diferentes graus de abertura estabelecidos pelo professor.

Em relação às atividades de demonstração, esses autores destacam que essas podem ser fechadas ou abertas. Enquanto as primeiras são caracterizadas pela simples ilustração de um fenômeno por parte do professor, as segundas podem apresentar características típicas das atividades investigativas, pois oferecem

\begin{abstract}
uma maior abertura e flexibilidade para discussões que podem permitir um aprofundamento nos aspectos conceituais e práticos relacionados com os equipamentos, a possibilidade de se levantar hipóteses e o incentive à reflexão crítica, de modo que a demonstração consistiria em um ponto de partida para a discussão sobre os fenômenos abordados, com possibilidade de exploração mais profunda do tema estudado. (ARAÚJO; ABIB, 2003, p. 181)
\end{abstract}

Essas atividades de demonstração abertas podem ser desenvolvidas com a utilização dos chamados equipamentos de baixo custo, materiais de fácil elaboração, que podem facilitar o trabalho do professor. Do ponto de vista do aluno, a utilização desses materiais pode proporcionar ao aluno o domínio de "todo o processo de conhecimento, através da construção, por seus próprios meios, dos aparatos que servirão de objeto de estudo" (SANTOS; PIASSI; FERREIRA, 2004, p. 8).

Usualmente, materiais de baixo custo têm a vantagem de dispensar ambientes especiais para a realização de atividades experimentais, tais como os laboratórios (SANTOS; PIASSI; FERREIRA, 2004, p. 7), o que, no entanto, não implica na realização de experimentos dispensados de planejamento prévio ou de ambientes minimamente apropriados. Para a proposta deste trabalho, por exemplo, deve-se considerar algumas características do ambiente em que se pretende fazer a prática de observação de espectros, de modo que o local não seja excessivamente iluminado, dificultando assim as observações. 
Porém, salientamos algumas precauções a serem tomadas quanto ao uso dos materiais de baixo custo em aulas de Ciências, de modo a evitar incorrer em determinados erros, como a crença exacerbada no uso desses materiais para solucionar os problemas do ensino experimental. Axt e Moreira (1991) questionam esse "costume" que pode levar o professor a um conformismo em relação à ausência de materiais e equipamentos de linha industrial, transformando o ensino experimental de Ciências numa espécie de "laboratório de sucata". Os autores não desconsideram a importância do uso de materiais de baixo custo para o desenvolvimento da criatividade dos alunos, porém, questionam a adesão acrítica e excessiva estima para com o uso desses materiais, em detrimento de materiais de qualidade superior, desenvolvidos especialmente para essas atividades.

A conveniência de aceitar uma solução de emergência como definitiva e de alertar para a componente ideológica contida na sugestão de que em países do terceiro mundo a solução para o ensino experimental de Ciências seria recorrer, necessariamente, ao material de baixo custo (AXT; MOREIRA, 1991, p. 99).

Ressaltamos que materiais dessa natureza têm o seu lugar nas aulas de Ciências, e podem favorecer o desenvolvimento de habilidades relacionadas à manipulação e construção de aparatos experimentais pelos alunos, a partir do uso de instrumentos comuns ao seu cotidiano. A nossa proposta centra-se no uso desses recursos para a construção de um instrumento simples, porém, rico em possibilidades de uso em sala de aula para abordar conceitos associados à Astronomia. Orientada por metodologias de ensino adequadas, essa atividade pode favorecer a interação professor-aluno (GASPAR; MONTEIRO, 2005), na troca de experiências e conhecimentos pertinentes aos conceitos relativos à espectroscopia, estrelas, natureza da luz, fenômenos ondulatórios, entre outros. Segundo Gaspar e Monteiro (2005),

\begin{abstract}
a atividade experimental de demonstração compartilhada por toda classe sob a orientação do professor, em um processo interativo que de certa forma simula a experiência vivencial do aluno fora da sala de aula, enriquece e fortalece conceitos espontâneos associados a essa atividade (talvez até os faça surgir) e pode oferecer os mesmos elementos de força e riqueza característicos desses conceitos para a aquisição dos conceitos científicos que motivaram a apresentação da atividade (p. 233).
\end{abstract}

\title{
II. Espectroscopia
}

A espectroscopia consiste no "estudo da luz através de suas cores componentes, que aparecem quando a luz passa através de um prisma ou de uma rede de difração" (OLIVEIRA FILHO; SARAIVA, 2007, p. 211). As origens da espectroscopia remontam ao início do século XIX, com o uso de fendas para a observação de espectros por William Wollaston (BOCHNIČEK, 2015, p. 1; PEDUZZI, 2008, p. 101). Em 1814, analisando o espectro solar, o óptico alemão Joseph Fraunhofer (1787-1826) observou mais de 600 de linhas escuras - denomina- 
das por ele de linhas de absorção -, ocasionadas pela absorção de determinadas cores por gases entre o Sol e a Terra (COMINS; KAUFMANN III, 2011, p. 109).

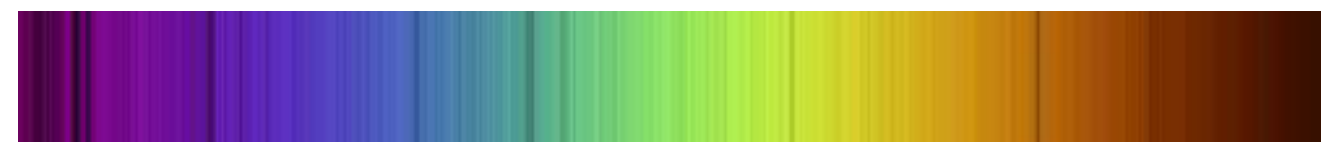

Fig. 1 - Espectro solar com as linhas escuras de Fraunhofer. Fonte: Hollow, 2006.

Posteriormente $^{5}$, G. R. Kirchhoff (1824-1887) e R. Bunsen (1811-1899) observaram que o espectro de emissão de um elemento químico seria característico desse, e que cada elemento apresentava espectros ${ }^{6}$ de emissão distintos ${ }^{7}$. Como resultado de diversos estudos sobre a análise espectral de elementos químicos, foram formuladas três leis da espectroscopia (OLIVEIRA; SARAIVA, 2007, p. 213): 1. Espectro de emissão contínuo: um corpo opaco quente, sólido, líquido ou gasoso, emite um espectro contínuo. Exemplo: nebulosas planetárias, constituídas por estrelas em seu estágio final de evolução. 2. Espectro de emissão discreto: um gás pouco denso produz um espectro de linhas brilhantes, conhecido como espectro de emissão discreto, de modo que o número e a cor dessas linhas dependem dos elementos químicos componentes do gás. Exemplo: nebulosas de emissão, que emitem luz devido à excitação causada por fótons de alta energia emitidos por jovens estrelas quentes. 3. Espectro de absorção: quando um espectro contínuo atravessa um gás a temperatura mais baixa, são produzidas algumas linhas escuras no espectro, conhecidas como linhas de absorção. Exemplo: nebulosas de absorção - também conhecidas como nebulosas escuras -, que impedem quase totalmente a passagem de luz por elas.

Estudando o espectro de emissão do Hidrogênio, o professor suíço Johann Balmer (1825-1898) identificou algumas linhas visíveis nesse espectro (que ficaram conhecidas posteriormente como séries de Balmer). Além das raias identificadas por Balmer, constatou-se que existiam outras linhas espectrais no átomo de Hidrogênio, também nomeadas como séries (Lyman, Paschen, Brackett e Pfund). Uma vez que cada átomo possui um espectro caracterís-

\footnotetext{
${ }^{5}$ Historicamente, vale ressaltar que o período antecedente ao nascimento de uma nova física (final do século XIX), diferentemente da versão popularizada de uma física "acabada" em que todos os problemas teriam sido resolvidos - salvo as famosas "nuvens negras" mencionadas por Kelvin -, foi, na realidade, marcado por grandes problemas associados à relação entre luz e matéria, resumidos em dois grandes temas: a natureza e a propagação das ondas eletromagnéticas (MATHIEU, 1971; MEDEIROS, 2002; KUHN, 1978).

6 Como veremos a seguir, essa característica permite aos cientistas determinar a composição química de um objeto astronômico distante a partir da identificação das linhas do seu espectro (COMINS; KAUFMANN III, 2011, p. 111).

7 De acordo com a Mecânica Quântica, as propriedades ondulatórias dos elétrons permitem que estes ocupem determinadas órbitas permitidas em torno do núcleo atômico (exceto para o caso da transição eletrônica de uma órbita permitida para outra). Por conseguinte, cada uma dessas órbitas possui níveis bem definidos de energia associados, de modo que cada átomo e molécula possui uma configuração exclusiva de órbitas permitidas (COMINS; KAUFMANN III, 2011, p. 116; MATHIEU, 1971, p. 216 - 217). Consequentemente, cada átomo possui um espectro de emissão característico.
} 
tico, podemos relacionar essas séries em uma expressão geral, onde a frequência $f$ das linhas é dada por (LEITE LOPES, 1992; YOUNG; FREEDMAN, 2009):

Quadro 1 - Exemplos de tipos de espectro. Fonte: Australia Telescope National Facility.

\begin{tabular}{|c|c|}
\hline Tipo de Espectro & Exemplo \\
\hline Emissão contínuo & \\
\hline Emissão discreto & \\
\hline Absorção & \\
\hline
\end{tabular}

$$
f=R_{H} c\left(\frac{1}{p^{2}}-\frac{1}{q^{2}}\right), p<q
$$

sendo $\mathrm{R}_{\mathrm{H}}$ uma constante ${ }^{8}, c$ a velocidade da luz e $p$ e $q$ correspondem aos níveis de energia do átomo de Hidrogênio. As séries de emissões para determinadas frequências são apresentadas no quadro a seguir.

Quadro 2 - Séries de linhas espectrais.

\begin{tabular}{|c|c|c|c|}
\hline $\mathbf{p}$ & $\mathbf{q}$ & Série & Faixa do espectro correspondente \\
\hline 1 & $2,3,4 \ldots$ & Lyman & Ultravioleta \\
\hline 2 & $3,4,5 \ldots$ & Balmer & Visível e Ultravioleta \\
\hline 3 & $4,5,6 \ldots$ & Paschen & \multirow{2}{*}{ Infravermelho } \\
\hline 4 & $5,6,7 \ldots$ & Brackett & \\
\hline 5 & $6,7,8 \ldots$ & Pfund & \\
\hline
\end{tabular}

A relação entre a produção de espectros e a estrutura atômica da matéria, sobretudo para o caso do átomo de Hidrogênio, recebeu contribuições de diversos cientistas da época, dentre eles o físico dinamarquês Niels H. Bohr (1885-1962), cujo modelo pôde explicar a estrutura atômica da matéria ${ }^{9}$, apesar de limitações.

\footnotetext{
${ }^{8}$ Constante de Rydberg. $R_{H}=1,0973 \cdot 10^{7} \mathrm{~m}^{-1}$.

${ }^{9}$ Um estudo pormenorizado sobre os modelos atômicos, especialmente o modelo de Bohr e a mecânica ondulatória, pode ser conferido em: DE BROGLIE, L. A física atômica e a física quântica contemporâneas. In.: TA-
} 


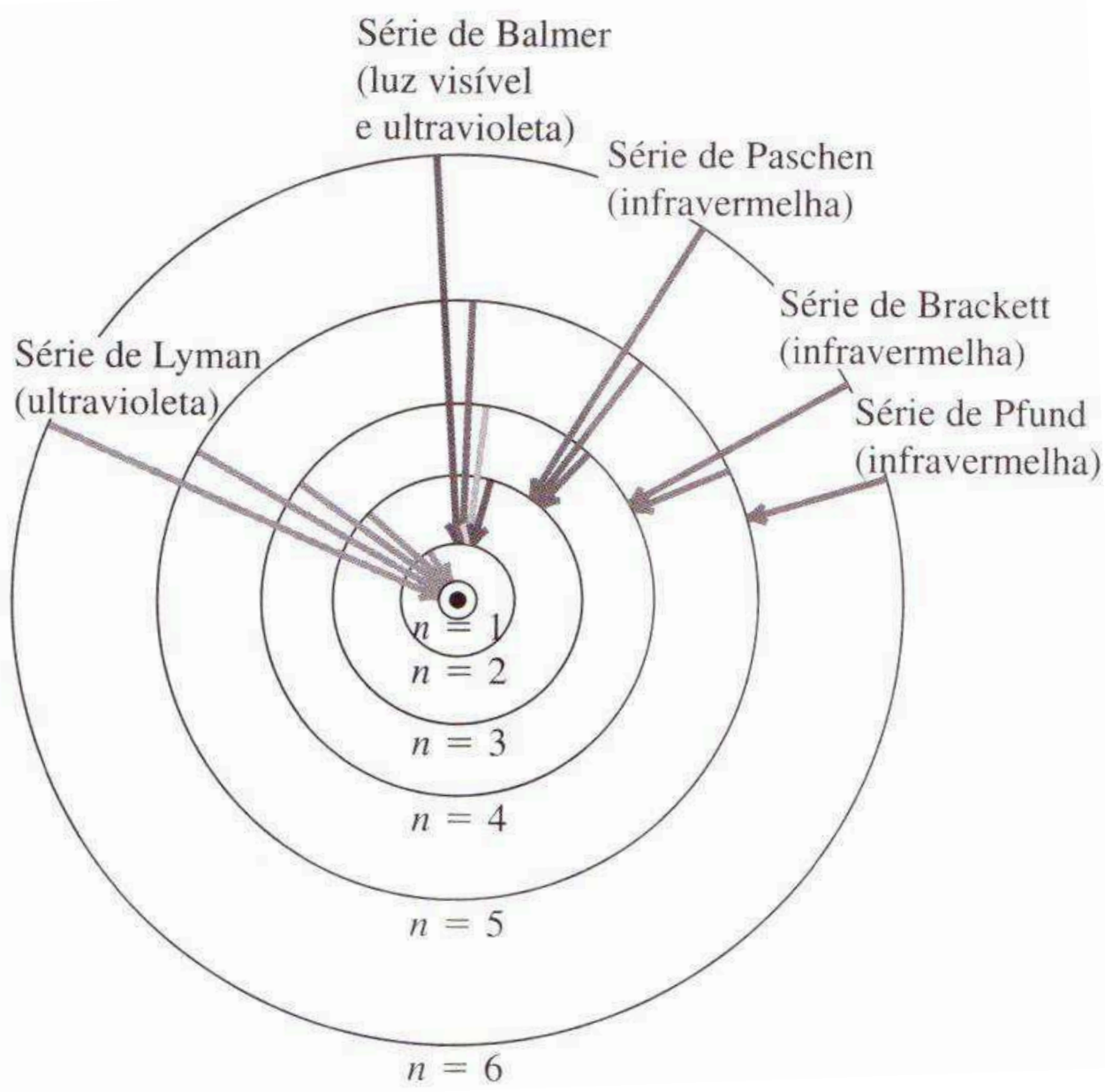

Fig. 2 - Ilustração do modelo de Bohr para o átomo de Hidrogênio. Fonte: Young \& Freedman, 2009, p. 187.

De acordo com a teoria clássica, a energia radiante emitida por uma carga acelerada provinha da energia mecânica dessa, fazendo com que a frequência de revolução do elétron aumentasse, aumentando também a frequência emitida, até que o elétron colidisse com o núcleo atômico; algo que, na realidade, não acontece. Bohr raciocinou que em determinados estados (ditos fundamentais) o átomo não emitiria radiação, mesmo que o elétron estivesse acelerado. No entanto, se o elétron recebesse uma energia (por exemplo, ao interagir com um fóton) de valor igual à diferença de energia entre o nível do estado fundamental e um segundo nível, o elétron deslocava-se para esse último nível (configurando um estado excitado), e re-

TON, R. (Org.). História Geral das Ciências: Tomo IV - A ciência no século XX. v. 1. São Paulo: Difusão Europeia do Livro, 1971, p. 132-148. 
tornaria para o estado fundamental em seguida ${ }^{10}$, emitindo em forma de fóton o "pacote" (quantum) de energia recebido anteriormente.

\section{II.1 Radiação do corpo negro}

À medida que aquecemos um corpo, uma barra metálica, por exemplo, fazemos com que ele emita radiação na forma de uma distribuição, de modo que a posição do máximo espectral (pico do gráfico, ver Fig. 3) muda com a temperatura e a potência irradiada. Visualmente, o aspecto do corpo aquecido muda, desde um tom avermelhado até tons mais claros, como amarelo e azul, indicando aumento da temperatura do material aquecido. Para o caso do espectro contínuo, haveria um corpo em especial que absorveria toda energia térmica nele incidente, reemitindo-a em forma de ondas eletromagnéticas, sendo esse conhecido como corpo negro. Um exemplo de grande proximidade com um corpo negro são os núcleos estelares que absorvem e emitem grandes quantidades de energia a uma taxa aproximadamente constante. Nesse corpo, a relação entre a intensidade da energia emitida I, em função do comprimento de onda $\lambda$, fornece uma grandeza denominada emitância espectral, que, por conseguinte, leva a uma relação entre o comprimento de onda $\lambda_{\text {máx }}$ e a temperatura absoluta $T$ do corpo, conhecida como Lei do deslocamento de Wien, dada por:

$$
\lambda_{\text {máx }} \cdot T=2,9 \cdot 10^{-3} \mathrm{~m} \cdot K
$$

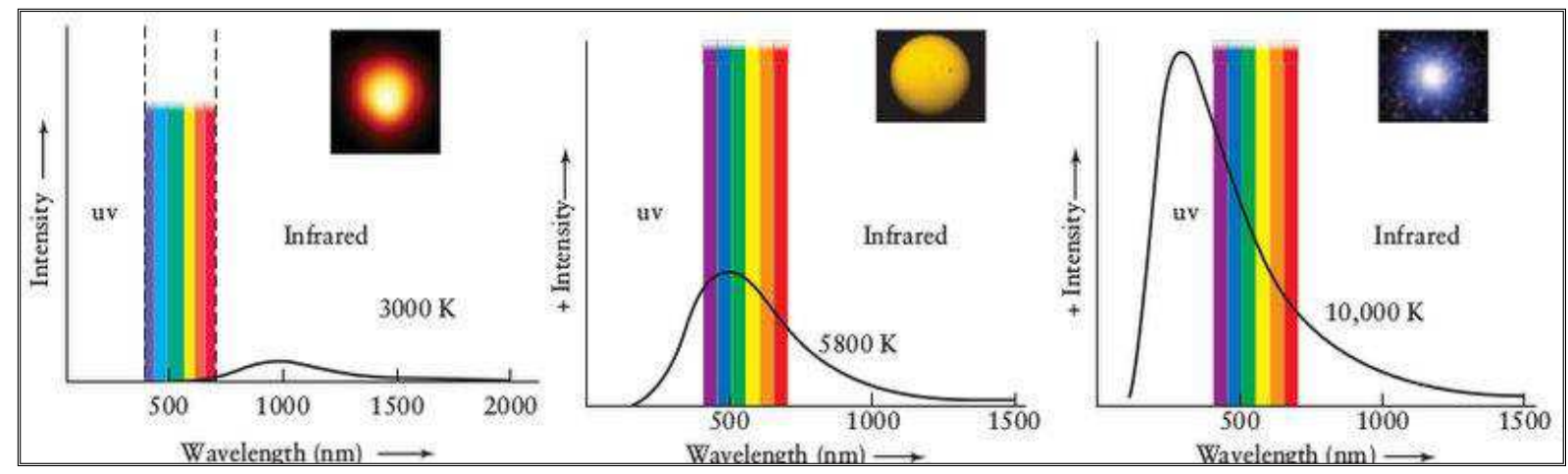

Fig. 3 - Relação entre a cor (frequência) de uma estrela e a temperatura da superfície para três tipos diferentes de estrelas. A localização do máximo espectral (pico do gráfico) muda de acordo com a temperatura da estrela, desde o infravermelho (estrela da esquerda) até o ultravioleta (estrela da direita). Fonte: COMINS; KAUFMANN, 2011, p. 325.

Utilizando a espectroscopia, astrônomos obtêm inúmeras informações que permitem caracterizar os astros, como por exemplo: rotação, composição química, densidade, massa,

\footnotetext{
10 O tempo entre uma transição do elétron para o estado excitado e retorno para o estado fundamental é estimado em $10^{-8}$ segundos.
} 
gravidade superficial, período, inclinação orbital, entre outras (HOLLOW, 2006, p. 1; DAFLON, 2011, p. 9; MARAN, 2011, p. 186).

\section{II.2 Exemplos de aplicação}

Para determinação de certa distância $d$ a uma estrela, astrônomos utilizam o método da paralaxe espectroscópica (ZEILIK; GREGORY; SMITH, 1992, p. 266) pela qual, a partir da análise do espectro da estrela, pode-se obter tanto a sua classificação espectral como a sua luminosidade. Por conseguinte, utilizando esses dados no Diagrama HR ${ }^{11}$, obtêm-se a magnitude aparente $m$, de modo que essa se relaciona com a magnitude absoluta $M$ da estrela, conforme a relação seguinte:

$$
m-M=5 \cdot \log (d)-5
$$

A análise espectral também permite obter a luminosidade de uma estrela e, consequentemente, o seu tamanho (OLIVEIRA FILHO; SARAIVA, 2004, p. 226), uma vez que há uma relação entre a largura das linhas espectrais e a gravidade superficial desses astros 12 , de modo que linhas mais alargadas indicam maior aceleração gravitacional superficial da estrela (Ibid., p. 227).

Utilizando análise espectral, é possível também obter o movimento relativo de um galáxia em relação a um observador localizado na Terra, graças ao efeito Doppler-Fizeau ${ }^{13}$. De maneira análoga à onda sonora, cuja frequência captada pelo observador depende do movimento relativo desse e da fonte, no efeito Doppler-Fizeau, o comprimento de onda detectado para a luz emitida por uma fonte, como uma estrela ou uma galáxia, varia conforme o movimento relativo desta. Por exemplo, para estrelas que estão se aproximando de um observador localizado na Terra, o comprimento de onda detectado tende a se deslocar para a região azul do espectro, recebendo esse efeito o nome blueshift (COMINS; KAUFMANN III, 2011, p. 118).

O comprimento de onda de uma dada linha espectral de uma estrela ou galáxia parecerá deslocado (comparando com uma fonte de laboratório em repouso) para o azul (ou vermelho) se ela estiver se aproximando (ou afastando) de nós. Medindo-se este deslocamento, podemos obter a velocidade de aproximação ou recessão do objeto. Dessa forma, os astrônomos descobriram que quanto mais distante a galáxia

\footnotetext{
11 O diagrama de Hertzsprung-Russell (conhecido comumente como diagrama "HR") consiste, basicamente, em um gráfico que relaciona a temperatura superficial da estrela com a sua luminosidade. Essa relação permite a identificação de diversos tipos de estrelas que se localizam em diferentes regiões do gráfico. No entanto, a maior parte das estrelas (incluindo o Sol) concentra-se em uma região estreita conhecida como sequência principal. Maiores detalhes sobre o diagrama HR, vide: < http://astro.if.ufrgs.br/estrelas/node2.htm>.

12 A dedução dessa relação pode ser encontrada em Filho e Saraiva (2004).

${ }^{13}$ Uma discussão pormenorizada sobre o Efeito Doppler-Fizeau encontra-se em Comins e Kaufmann III (2011, p. 118-121).
} 
ou quasar maior era o deslocamento para o vermelho de espectro observado: vivemos em um Universo em expansão (MAGALHÃES, 2008, p. 34).

A análise espectral permitiu aos astrônomos a elaboração e aperfeiçoamento da classificação das estrelas em determinadas categorias (O-B-A-F-G-K-M), de acordo com a temperatura superficial da estrela. Cada uma dessas categorias agrupa outras dez subcategorias.

Quadro 3. Classificação espectral das estrelas. Fonte: COMINS; KAUFMANN, 2011, p. 328.

\begin{tabular}{|c|c|c|c|c|}
\hline $\begin{array}{c}\text { Classe } \\
\text { espectral }\end{array}$ & Cor & Temperatura (K) & Linhas espectrais & $\begin{array}{c}\text { Exemplos de estrelas da } \\
\text { categoria }\end{array}$ \\
\hline $\mathrm{O}$ & Azul-violeta & $30000-50000$ & $\begin{array}{l}\text { Átomos ionizados, } \\
\text { especialmente } \\
\text { Hélio }\end{array}$ & $\begin{array}{c}\text { Naos ( } \xi \text { Puppis) } \\
\text { Mintaka ( } \delta \text { Orionis) }\end{array}$ \\
\hline B & Azul-branco & $11000-30000$ & $\begin{array}{c}\text { Hélio neutro, pouco } \\
\text { hidrogênio }\end{array}$ & $\begin{array}{l}\text { Spica ( } \alpha \text { Virginis) } \\
\text { Rigel ( } \beta \text { Orionis })\end{array}$ \\
\hline A & Branco & $7500-11000$ & $\begin{array}{l}\text { Majoritariamente } \\
\text { hidrogênio, alguns } \\
\text { metais ionizadose }\end{array}$ & $\begin{array}{c}\text { Sirius ( } \alpha \text { Canis Majoris) } \\
\text { Vega ( } \alpha \text { Lirae })\end{array}$ \\
\hline $\mathrm{F}$ & $\begin{array}{l}\text { Amarelo- } \\
\text { Branco }\end{array}$ & $5900-7500$ & $\begin{array}{l}\text { Metais neutros e } \\
\text { ionizados, tais } \\
\text { como Cálcio e } \\
\text { Ferro }\end{array}$ & $\begin{array}{c}\text { Canopus ( } \alpha \text { Carinae }) \\
\text { Procyon }(\alpha \text { Canis } \\
\text { Minoris })\end{array}$ \\
\hline G & Amarelo & $5200-5900$ & $\begin{array}{l}\text { Metais neutros e } \\
\text { ionizados, } \\
\text { principalmente } \\
\text { Cálcio ionizado }\end{array}$ & Sol, Capella ( $\alpha$ Aurigae) \\
\hline $\mathrm{K}$ & Laranja & $3900-5200$ & Metais neutros & $\begin{array}{l}\text { Arcturus ( } \alpha \text { Boötis }) \\
\text { Aldebaran }(\alpha \text { Tauri) }\end{array}$ \\
\hline M & $\begin{array}{l}\text { Vermelho- } \\
\text { laranja }\end{array}$ & $2500-3900$ & $\begin{array}{c}\text { Principalmente } \\
\text { óxido de Titânio e } \\
\text { pouco Cálcio } \\
\text { neutro }\end{array}$ & $\begin{array}{c}\text { Antares ( } \alpha \text { Scorpii }) \\
\text { Betelgeuse ( } \alpha \text { Orionis })\end{array}$ \\
\hline
\end{tabular}

Consideramos tais exemplos suficientes para evidenciar a importância da espectroscopia na Astronomia, de sorte que, face à limitada extensão do trabalho e complexidade de determinadas técnicas utilizadas na Astronomia, omitimos aqui os demais exemplos de aplicação da espectroscopia, podendo ser encontrados em livros da área como os que estão referenciados neste trabalho. Não é exagero dizer que quase tudo o que sabemos sobre o universo se deve ao uso dessa técnica. Combinada com a fotografia, a espectroscopia levou ao nascimento de uma nova área da Astronomia, a Astrofísica, na segunda metade do século XIX (HOLLOW, 2006, p. 1). 


\section{Construção do espectroscópio}

O espectroscópio é um instrumento ${ }^{14}$ utilizado para decomposição e análise da luz emitida por uma determinada fonte. Ao passar por uma rede de difração, a luz é decomposta em seus componentes do espectro. Uma vez que cada elemento químico possui um espectro característico, a análise espectral de uma determinada fonte luminosa revela características como a composição química da mesma.

Para construção do espectroscópio, serão necessários os seguintes materiais:

- Tubo de papelão

- Mídia CD ou DVD

- Papel cartão preto

- Fita isolante ou fita adesiva

- Estilete

Esses materiais podem ser encontrados em papelarias ou outros estabelecimentos comerciais. O tubo de papelão também pode ser obtido a partir de materiais recicláveis, tais como, uma caixa de pasta de dente, tubos de papel vegetal ou papel toalha, etc.

\section{III.1 Montagem}

III.1.1 Comece a montagem do seu espectroscópio retirando a película refletora da superfície do DVD ou CD. Para isso, utilize o estilete com cuidado, para fazer pequenos sulcos na superfície do disco, como mostrado na Fig. 4. Em seguida, recorte alguns pedaços de fita isolante e cole na superfície do CD. Esfregue a fita isolante com a unha de modo que essa adira à superfície.

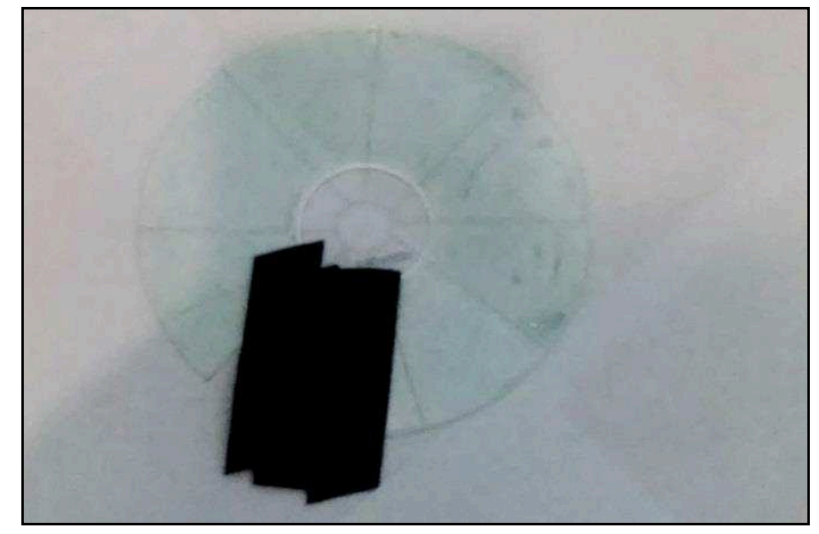

Fig. 4 - Removendo a película refletora do CD.

\footnotetext{
${ }^{14}$ Há, no entanto, uma diferença relativamente simples entre espectroscópio e espectrógrafo. Ambos utilizam o mesmo princípio para produção do espectro da luz a ser analisado (luz incidente em uma rede de difração). No entanto, com a invenção da fotografia, os astrônomos passaram a registrar os espectros coletados pelos espectroscópios em chapas fotográficas, levando assim ao nascimento do espectrógrafo. Por ser mais sofisticado que o espectroscópio, o espectrógrafo é o instrumento mais utilizado pelos astrofísicos atualmente (MOURÃO, 1987, p. 280).
} 
III.1.2 Retire a fita isolante com cuidado, removendo a película refletora do CD.

III.1.3 Utilize a tesoura para recortar um pequeno pedaço do $\mathrm{CD}$, de aproximadamente 1 x $2 \mathrm{~cm}$. Será essa peça a nossa rede de difração. Detalhe: o recorte deve ser realizado o mais distante possível do centro do $\mathrm{CD}$, a fim que consigamos obter um pedaço em que as trilhas sejam menos curvas, fazendo assim com que o pedaço de CD se comporte como uma rede de difração.

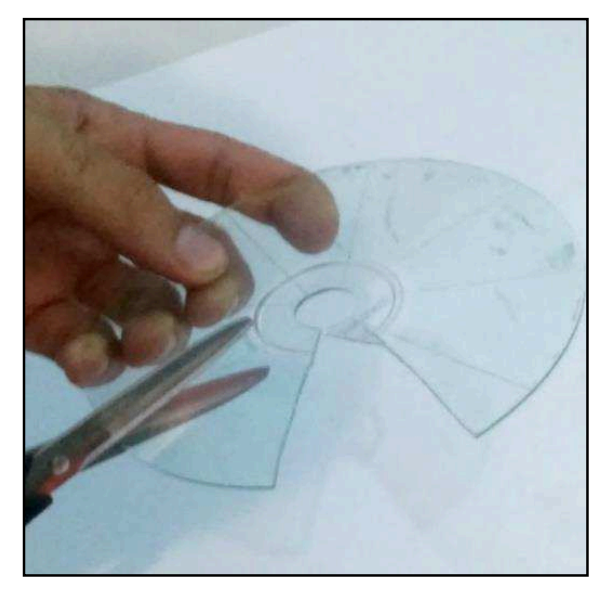

Fig. 5 - Recortando a rede de difração do $C D$.

III.1.4 Recorte dois pedaços de papel cartão de dimensões iguais às das extremidades da caixa de pasta de dente. Utilize a fita isolante para fixar os pedaços nas extremidades da caixa. Em uma das extremidades, faça uma pequena abertura de dimensões 0,7 x 1,7 cm, no pedaço de papel cartão, utilizando estilete. Em seguida, usando fita isolante, fixe a rede de difração nesse local. As trilhas do $\mathrm{CD}$, que farão o papel das fendas da rede de difração, devem ser posicionadas de modo que coincidam com a orientação da fenda. Do contrário, o espectro ficará bastante deformado.

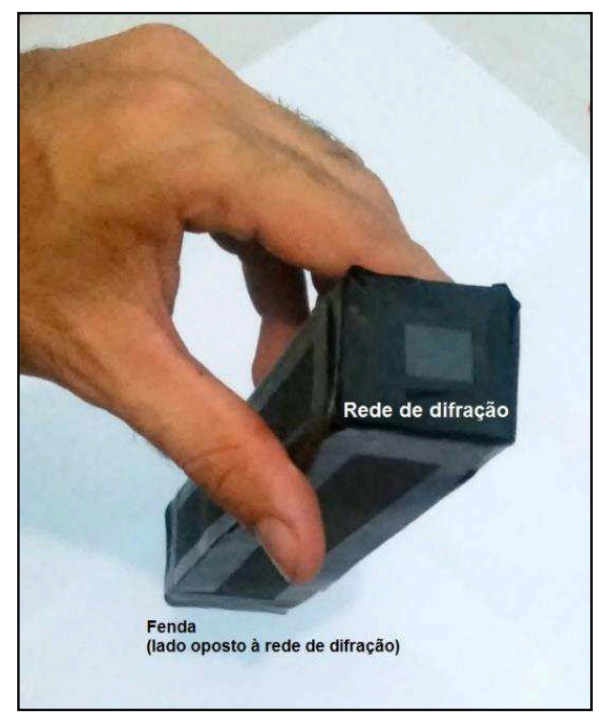

Fig. 6. 
III.1.5 Na outra extremidade, utilizando estilete, faça uma pequena fenda, com largura de até 0,5 milímetro, e comprimento de 0,8 centímetros. OU: Uma alternativa ao estilete, que pode assegurar maior qualidade na imagem das linhas espectrais, é a montagem da fenda colando-se dois pedaços de fita isolante, bem próximos entre si e exatamente paralelos. Isso evitaria deformações no corte causadas pelo estilete.

III.1.6 Utilize o papel cartão e a fita isolante para revestir a superfície externa tubo de papelão. Seu espectroscópio está pronto!

Experimente seu espectroscópio apontando para alguns tipos de fontes luminosas: lâmpadas (fluorescentes, incandescentes, halogêneos, de vapor de sódio, etc.), telas de aparelhos eletrônicos (computadores, celulares, televisores, etc.), projetores de slides, retroprojetores, velas, postes de iluminação pública, de monumentos, lâmpadas de $\mathrm{LED}^{15}$, entre outras. Lembre-se: você deve apontar a fenda do seu espectroscópio para a fonte de luz, e observar o espectro através da rede de difração, localizada no lado oposto do instrumento.

ATENÇÃO: Para observação do espectro da luz solar, direcione seu espectroscópio para uma região clara do ambiente (parede branca, nuvens, etc.). NUNCA aponte o espectroscópio em direção ao Sol, pois isso acarretará sérios danos à sua visão! Em caso de dúvidas quanto ao uso seguro do instrumento, solicite orientações ao seu professor.

A seguir, são apresentadas algumas questões como sugestões de problemas que o professor poderá explorar com os alunos após a construção do espectroscópio.

(1) Escolha até 5 (cinco) diferentes tipos de fontes luminosas para observação do espectro, e aponte seu espectroscópio. Descreva e desenhe o espectro observado de cada uma delas. Se você disponibilizar de câmera fotográfica ou aparelho celular equipado com câmera, utilize-o para fotografar os espectros que você observou.

(2) Como você interpreta os espectros observados? Haveria diferenças entre eles? Por quê?

(3) Você saberia dizer de quais tipos foram os espectros por você observados (emissão contínuo, emissão discreto, absorção)?

4) Você conseguiria estimar a composição química das fontes luminosas observadas com seu espectroscópio? De que forma?

\section{Algumas imagens obtidas com o espectroscópio de baixo custo}

Utilizando o espectroscópio que construímos, é possível obter as imagens dos espectros de algumas fontes luminosas. Obviamente, o espectro observado com esse instrumento rudimentar (se comparado com os modernos espectrógrafos) é diferente daqueles apresenta-

\footnotetext{
${ }^{15}$ Sigla em inglês para Diodo Emissor de Luz.
} 
dos no catálogo de imagens, uma vez que a rede de difração utilizada (CD ou DVD) não tem trilhas retas, comprometendo assim o padrão de formação de espectros.

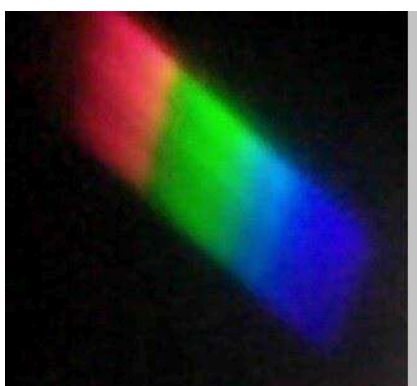

A

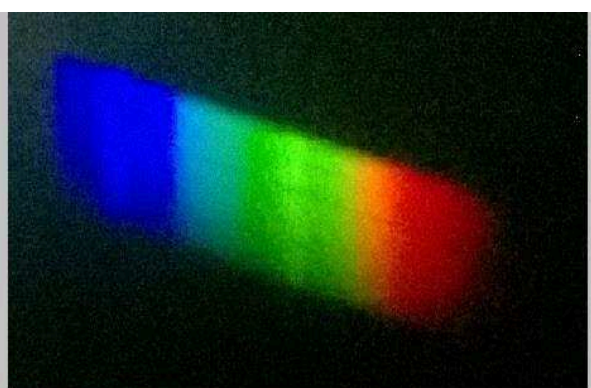

B

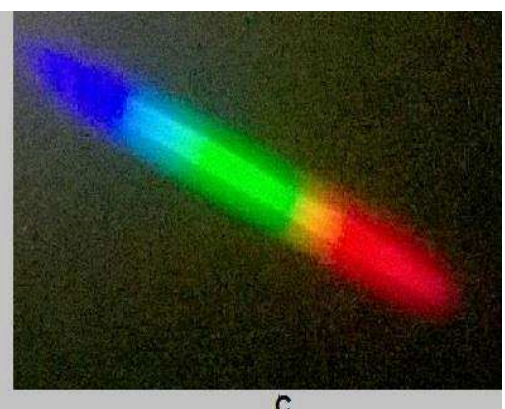

C

Fig. 7. Espectros obtidos para a luz do Sol (A), lâmpada fluorescente (B) e lâmpada de halogêneo $(C)$.

\section{IV.1 Catálogo de imagens}

Quadro 4. Representação artística do espectro de emissão de alguns elementos químicos ${ }^{16}$.

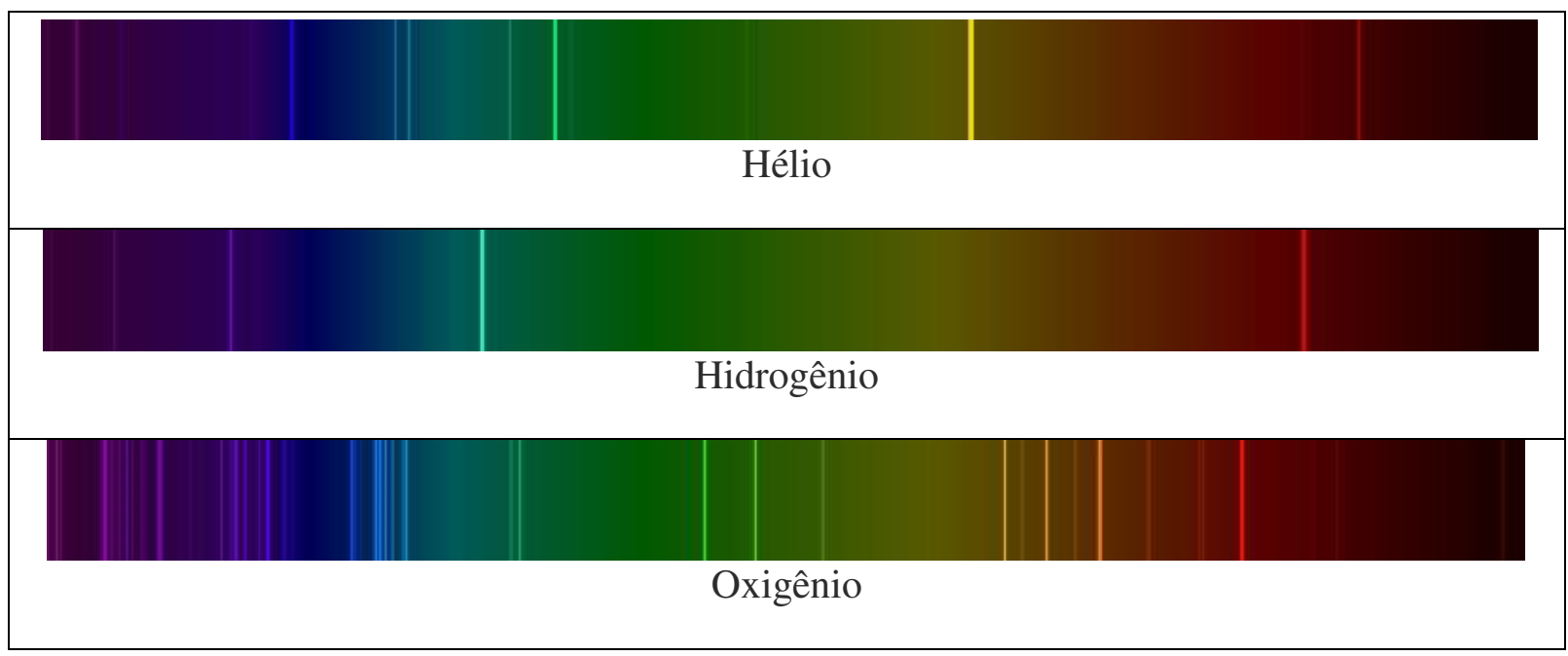

\section{Considerações finais}

A fim de enriquecer e diversificar a abordagem da espectroscopia em sala de aula, o professor pode também recorrer ao teste da chama (SALCIDES; PRATA, 2011) para demonstração da cor da chama característica de determinados compostos (ex. magnésio, cloreto

\footnotetext{
16 As imagens dos espectros foram retiradas de <http://astro.u-strasbg.fr/ koppen/discharge/index.html>. Acesso em: 25 jan. 2016.
} 
de sódio, etc.). Na ausência de materiais para o teste da chama, o professor pode também providenciar imagens ${ }^{17}$ da chama de diferentes compostos químicos.

Recomenda-se também a utilização de diferentes fontes luminosas em sala de aula para a verificação dos espectros por parte dos alunos, com o uso do espectroscópio construído por eles, tais como: lâmpadas (fluorescentes, incandescentes, vapor de sódio, vapor de mercúrio, iodetos metálicos, halogênio, neônio, LED, etc.), aparelhos para projeção (retroprojetores e projetores de slides) e telas de aparelhos eletroeletrônicos (monitores de computador, tablets, smartphones, etc.). É possível, ainda, articular a espectroscopia com o estudo de circuitos elétricos, no qual os estudantes construiriam seus próprios circuitos para ligação de lâmpadas, cuja luz emitida poderia ser analisada pelo espectroscópio.

As questões propostas ao final da construção do experimento têm como objetivo suscitar discussões em sala de aula ao fazer com que os alunos utilizem os seus instrumentos recém-construídos para identificação dos espectros de diferentes fontes luminosas, possibilitando ao professor, no âmbito do ensino de conceitos de Astronomia, a abordagem da composição química estelar ao destacar a espectroscopia como ferramenta de estudo desses astros (temperatura, rotação e outras características). Dado o grande potencial interdisciplinar, a espectroscopia pode constituir uma rica sequência didática no ensino de Astronomia, interagindo diretamente com conteúdos de outras áreas, como por exemplo, da Física Moderna e da Química.

Apesar de a espectroscopia ser uma técnica sofisticada e o espectroscópio (ou espectrógrafo) uma ferramenta poderosa para estudo da composição química dos astros, é possível que o próprio estudante construa o aparelho que, apesar de simples, é baseado no mesmo princípio dos modernos instrumentos (decomposição da luz incidente em uma rede de difração), utilizando poucos materiais de fácil acesso e custo baixo. Tendo em vista possuir grande potencial didático e pedagógico, o espectroscópio permite ao professor abordar diferentes temas dentro da Física, Química e Astronomia, como por exemplo: natureza da luz; fenômenos ondulatórios (difração, polarização e interferência); princípio de Huygens; técnicas observacionais; magnitude aparente e magnitude absoluta dos astros; fotometria; óptica geométrica; ondas eletromagnéticas; cosmologia; descoberta de novos elementos químicos; primórdios da teoria quântica; história da química; radiação térmica, entre outros.

A observação desses diferentes espectros de luz no Ensino Médio certamente levará a uma discussão aprofundada não somente sobre a natureza da luz, mas também sobre o desenvolvimento da Física e Química modernas, ressaltando a contribuição desse tipo de análise no surgimento de modelos atômicos (CAVALCANTE; TAVOLARO, 2002, p. 40).

17 Um exemplo de demonstração de chama de diferentes compostos químicos pode ser encontrado em: <https://i.ytimg.com/vi/9dqFfE1RebA/maxresdefault.jpg>. Acesso em: 12 fev. 2016. 
Por fim, é possível, também, articular o uso do espectroscópio com outras propostas de abordagem no ensino de física, como por exemplo, a inserção de conceitos de Física Moderna no Ensino Médio utilizando a Abordagem Temática, na qual uma situação ou episódio local são tomados como ponto de partida para a estruturação de sequências didáticas associadas ao ensino e à aprendizagem de conceitos de Física Moderna (MIGUEL, 2010).

\section{Agradecimentos}

Os autores agradecem a Fundação CAPES pelo apoio financeiro, e árbitros do Caderno Brasileiro de Ensino de Física, pela análise, críticas e sugestões pertinentes a este trabalho.

\section{Referências}

ARAUJO, M. S. T.; ABIB, M. L. V. S. Atividades experimentais no Ensino de Física: Diferentes enfoques, diferentes finalidades. Revista Brasileira de Ensino de Física, v. 25, n. 2, p. 176-194, 2003.

AUSTRALIA TELESCOPE NATIONAL FACILITY. How are Spectra Produced? Disponível em: <http://goo.gl/ghdVEI>. Acesso em: 26 jan. 2016.

AXT, R.; MOREIRA, M. A. O ensino experimental e a questão do equipamento de baixo custo. Caderno Brasileiro de Ensino de Física, v. 13, p. 97-104, dez. 1991.

BOCHNIČEK, Z. Linear halogen bulb as a powerful light source for physics experiments. European Journal of Physics, v. 36, 2015.

BRASIL, 2000. Secretaria de Educação. Orientações Educacionais Complementares aos Parâmetros Curriculares Nacionais. Disponível em: <http://www.sbfisica.org.br/arquivos/PCN_FIS.pdf>. Acesso em: 20 jan. 2016.

CANAlle, J. B. G. O problema do ensino da órbita da Terra. Física na Escola, v. 4, n. 2, p. 12-16, 2003.

CANIATO, R. (Re)Descobrindo a Astronomia. Campinas: Editora Átomo, 2013.

CAVAlCANTE, M. A.; TAVOLARO, C. R. C. Uma caixinha para estudo de espectros. Física na Escola, v. 3, n. 2, p. 40-42, 2002.

COMINS, N. F.; KAUFMANN III, W. J. Discovering the Universe. New York: W. H. Freeman and Company, 2011.

DAFLON, S. Astrofísica Observacional. Notas de aula - Escola de Inverno - Astronomia. Rio de Janeiro: Observatório Nacional, 2011. 
FERREIRA, A. C. et. al. Physical Science Study Committee (2011). Disponível em: $<$ http://goo.gl/WRin8n>. Acesso em: 20 jan. 2016.

GASPAR, A.; MONTEIRO, I. C. C. Atividades experimentais de demonstrações em sala de aula: uma análise segundo o referencial da teoria de Vygotsky. Investigações em Ensino de Ciências, Porto Alegre, v. 10, n. 2, p. 227-254, 2005.

HODSON, D. Philosophy of Science, Science and Science Education. Studies in Science Education, n. 12, p. 25-57, 1985.

HOLLOW, R. Spectroscopy: unlocking the Secrets of Star Light. Science Teacher's Workshop. Australia, 2006.

KUHN, T. S. Black-Body Theory and the Quantum Discontinuity (1894-1912). New York: Oxford University Press, 1978.

LANGHI, R. Astronomia nos anos iniciais do Ensino Fundamental: repensando a formação de professores. 2009. Tese. Doutorado (Educação para a Ciência) - UNESP, Bauru, SP.

LANGHI, R.; NARDI, R. Dificuldades interpretadas nos discursos de professores dos anos iniciais do Ensino Fundamental em relação ao Ensino de Astronomia. Revista LatinoAmericana de Educação em Astronomia, n. 2, p. 75-92, 2005.

LANGHI, R.; NARDI, R. Ensino de Astronomia: erros conceituais mais comuns presentes em livros didáticos de Ciências. Caderno Brasileiro de Ensino de Física, v. 24, n. 1, p. 87-111, 2007.

LANGHI, R.; NARDI, R. Educação em Astronomia: repensando a formação de professores. São Paulo: Escrituras Editora, 2012.

LANGHI, R. Propostas de atividades práticas de astronomia para o ensino fundamental. In: SILVA, J. A.; BARTELMEBS, R. C. Pesquisas e práticas para o ensino de ciências nos anos iniciais. Curitiba: Editora CRV, 2014. p. 57-71.

LEITE LOPES, J. Do átomo pré-socrático às partículas elementares: a estrutura quântica da matéria. Rio de Janeiro: Editora da UFRJ, 1992.

MAGAlHÃES, A. M. As ferramentas do astrônomo. In.: FRIAÇA, A. S. et. al. (Org.). Astronomia: uma visão geral do Universo. São Paulo: EDUSP, 2008. p. 22-34.

MARAN, S. P. Astronomia para leigos. Rio de Janeiro: Alta Books, 2011.

MATHIEU, J. P. A espectroscopia. In.: TATON, R. (Org.). História Geral das Ciências, tomo IV: A Ciência no Século XIX. São Paulo: Difusão Europeia do Livro, 1971. p. 210-220. 
MEDEIROS, A. A história da ciência e o ensino de Física. Revista do Departamento de Educação da UFAL, 2005.

MIGUEL, J. C. A Física Moderna no Ensino Médio: Articulações entre os momentos pedagógicos e a significação conceitual. Trabalho de conclusão de Curso. Campo Grande - MS: UFMS, 2010.

MOURÃO, R. R. F. Dicionário Enciclopédico de Astronomia e Astronáutica. Rio de Janeiro: Editora Nova Fronteira, 1987.

OLIVEIRA FILHO, K. S.; SARAIVA, M. F. Astronomia e Astrofísica. São Paulo: Editora Livraria da Física, 2004.

PACHECO, D. A Experimentação no Ensino de Ciências. Ciência \& Ensino, São Paulo, v. 2, jun. 1997.

PEDUZZI, L. O. Q. Evolução dos Conceitos da Física: do átomo grego ao átomo de Bohr. Florianópolis: UFSC, 2008.

PENA, F. L. A.; RIBEIRO FILHO, A. Obstáculos para o uso da experimentação no ensino de Física: um estudo a partir de relatos de experiências pedagógicas brasileiras publicados em periódicos nacionais (1971-2006). Revista Brasileira de Pesquisa em Educação em Ciências, v. 9, n. 1, p. 1-13, 2009.

REZENDE JR, M. F.; CRUZ, F. F de S. Física moderna e contemporânea na formação de licenciandos em Física: necessidades, conflitos e perspectivas. Ciência e Educação, v. 15, n. 2, p. 305-321, 2009.

SALCIDES, P. F.; PRATA, L. A. Proposta de uma aula interdisciplinar de Química e Astronomia: Espectroscopia. In: SIMPÓSIO NACIONAL DE EDUCAÇÃO EM ASTRONOMIA, 1, 2011, Rio de Janeiro. Atas... Sociedade Astronômica Brasileira, 2011.

SANTOS, E. I.; PIASSI, L. P. C.; FERREIRA, N. C. Atividades experimentais de baixo custo como estratégia de construção da autonomia de professores de Física: uma experiência em formação continuada. In: ENCONTRO DE PESQUISA EM ENSINO DE FÍSICA, 9, 2004, Jaboticatubas, MG. Atas... Sociedade Brasileira de Física, 2004.

SILVA, L. F.; ASSIS, A. Física Moderna no Ensino Médio: um experimento para abordar o efeito fotoelétrico. Caderno Brasileiro de Ensino de Física, Florianópolis, v. 29, n. 2, p. 313-324, 2012.

YOUNG, H. D.; FREEDMAN, R. Física IV: Ótica e Física Moderna. São Paulo: AddisonWesley, 2009. 
ZEILIK, M.; GREGORY, S. A.; SMITH, E. V. P. Introductory Astronomy and Astrophysics. Fort Worth: Saunders, 1992. 